\title{
STUDYING THE CHANGES IN THE STRUCTURE AND PROPERTIES OF A MAGNE- SIUM ALLOY AFTER OPERATION AND LONG ANNEALING AT TEMPERATURES OF 50 AND $70{ }^{\circ} \mathrm{C}$
}

\author{
N. B. Pugacheva ${ }^{1}$, D. I. Vichuzhanin ${ }^{1}$, S. V. Smirnov ${ }^{1}$, S. T. Kalashnikov ${ }^{2}$, V. S. Chekushkin ${ }^{2}$, \\ N. P. Antenorova ${ }^{1}$, A. A. Pankratov ${ }^{3}$ \\ ${ }^{1}$ Institute of Engineering Science, Ural Branch of the Russian Academy of Sciences, 34 Komsomolskaya st., Ekaterin- \\ burg, Russian Federation \\ 2 "Academician V.P. Makeev State Rocket Centre” Open Joint Stock Company, 1 Turgoyakskoe shosse, Miass, Chelya- \\ binskaya oblast, Russian Federation \\ ${ }^{3}$ Institute of High-Temperature Electrochemistry, Ural Branch of the Russian Academy of Sciences, \\ 20 Akademicheskaya st., Ekaterinburg, Russian Federation
}

*Corresponding author. E-mail: nat@imach.uran.ru ; address for correspondence: ul. Komsomolskaya 34, Ekaterinburg, Russian Federation. Tel.:375-35-91; fax: 374-53-30.

The microstructure and mechanical properties of magnesium alloy samples cut out from a shell structure after 20 years' operation in climatic conditions are studied, as well as the effect of subsequent annealing at temperatures of 50 and $70{ }^{\circ} \mathrm{C}$ during up to $3000 \mathrm{~h}$ on the change in the mechanical properties and the values of electrical resistivity. The magnesium alloy is shown to consist of an $\alpha$-solid solution of alloying elements in magnesium, a $\beta$-solid solution of alloying elements in lithium, and intermetallic compounds of aluminum, zinc, magnesium, manganese and lithium. At the studied temperatures, the aging processes in the alloy proceed extremely inertly, with an insignificant decrease in hardness and unchanged values of electrical resistivity. Changes in mechanical properties are recorded only within the first 1000 hours of annealing at $70{ }^{\circ} \mathrm{C}$.

Keywords: magnesium alloy, microstructure, intermetallic compound, hardness, strength, aging, electrical resistivity

DOI: $10.17804 / 2410-9908.2015 .4 .029-041$

\section{References}

1. Kolachev B.A., Elagin V.I., Livanov V.A. Metallovedenie i termicheskaya obrabotka tsvetnykh metallov i splavov. [Metal Science and Heat Treatment of Non-Ferrous Metals and Alloys]. Moscow: MISIS Publ., 2001, 416 p. (In Russian).

2. Mashinostroenie. Entsiklopediya. [Mechanical Engineering. Encyclopedia], Vol. II-3. I.N. Fridlyander, eds. Tsvetnye metally i splavy. Kompozitsionnye metallicheskie materialy [NonFerrous Metals and Alloys. Composite Metallic Materials]. Moscow: Mashinostroenie Publ., 2001, 880 p. (In Russian).

3. Fridlyander I.N. Advanced aluminum, magnesium alloys and composite materials based on them - Metallovedenie i Termicheskaya Obrabotka Metallov, 2002, no. 7, pp. 24 - 29. (In Russian). 4. $\quad$ Drits M.E., Padezhnova E.M., Rokhlin A.I. Legkie splavy, soderzhashchie litiy [LithiumContaining Light Alloys], N.Kh Abrikosov, ed. / Moscow: Nauka Publ., 1982, 143 p. (In Russian).

5. G.V. Samsonov, ed. Svoystva elementov: $v 2 t$. [Properties of Elements. In 2 volumes] // edited by - Moscow: Metallurgiya Publ., 1976, vol. 1, 600 p.; vol. 2, 383 p. (In Russian).

6. Magnievye splavy. Spravochnik. Ch. 1. Metallovedenie magniya i ego splavov. Oblasti primeneniya [Magnesium Alloys. Reference Book. Part 1. Metal Science of Magnesium and its Alloys. Applications]. Moscow: Metallurgiya Publ., 1978, 232 p. (In Russian).

Pugacheva N.B. et al. / Studying the changes in the structure and properties of a magnesium alloy after operation and long annealing at temperatures of 50 and $70^{\circ} \mathrm{C}$ 
7. Turkin V.D, Rumyantsev M.V. Struktura i svoystva tsvetnykh metallov. [Structure and Properties of Non-Ferrous Metals]. Moscow: GNILChTsM Publ., 1947, 440 p. (In Russian).

8. Dorokhina L.N., Tauzhnyanskaya Z.A., Nikerova L.F., Krucher G.N. Legkie tsvetnye metally $i$ splavy: spravochnik [Light Non-Ferrous Metals and Alloys. Reference Book], S.N. Podvishensky and M.V. Teslitskaya, ed. Moscow: FGUP "CNIIEtsvetmet” Publ., 2001, vol. 2, 416 p. (In Russian).

9. L.K. Martens, eds. Tekhnicheskaya entsiklopediya [Technical Encyclopedia]. Moscow: Gostekhizdat OGIZ Publ., 1941, vol. 12, 855 p. (In Russian).

10. Mirzaev D.A., Karyagin Yu.D., Dobrynina Ya.S., Zvonkov A.A. Studying and simulating recovery in the AMg6 alloy in order to predict the service life of aerospace parts. Fizika Metallov $i$ Metallovedenie, 2004, vol. 98, no. 8, pp. 11 - 18 (In Russian).

11. Mirzaev D.A., Karyagin Yu.D., Okishev K.Yu., Elgin V.M., Zvonkov A.A. Predicting a change in yield stress caused by diffusion transformations in the MA21 alloy during hold time of many years. Vestnik Yuzhno-Uralskogo Gosudarstvennogo Universiteta. Seriya: Matematika. Mekhanika. Fizika, 2006, no. 7, pp 199 - 202. (In Russian).

12. Rokhlin L.L. Studying the kinetics of the decay of a satiated solid solution in magnesiumyttrium alloys. Metallovedenie i Termicheskaya Obrabotka Metallov, 1987, no. 3. pp. 50 - 52 (In Russian). 
Подана в журнал: 18.08 .2015

УДК 620.18.186:539.4.016:620.172

DOI: $10.17804 / 2410-9908.2015 .4 .029-041$

\title{
ИССЛЕДОВАНИЕ ИЗМЕНЕНИЙ СТРУКТУРЫ И СВОЙСТВ СПЛАВА МА21 ПОСЛЕ ЭКСПЛУАТАЦИИ И ДЛИТЕЛЬНЫХ ВЫДЕРЖЕК ПРИ ТЕМПЕРАТУРАХ 50 И $70{ }^{\circ} \mathrm{C}$
}

\author{
Н. Б. Пугачева ${ }^{1}$, Д. И. Вичужанин ${ }^{1}$, С. В. Смирнов ${ }^{1}$,С. Т. Калашников ${ }^{2}$, \\ В. С. Чекушкин ${ }^{2}$, Н. П. Антенорова ${ }^{1}$, А. А. Панкратов ${ }^{3}$ \\ ${ }^{l}$ Федеральное государственное бюджетное учреждение науки Институт машиноведения Уральского \\ отделения Российской академии наук, г. Екатеринбург, ул. Комсомольская, 34 \\ ${ }^{2}$ Акиионерное общество «Государственный ракетный центр имени академика В.П. Макеева», Челя- \\ бинская область, г. Миасс, Тургоякское шоссе, 1 \\ ${ }^{3}$ Федеральное государственное бюджетное учреждение науки Институт высокотемпературной \\ электрохимии УрО РАН, г. Екатеринбург, ул. Академическая, 20
}

* Ответственный автор. Электронная почта: nat@imach.uran.ru; адрес для переписки: ул. Комсомольская, 34, Екатеринбург, Российская Федерация. Телефон: 375-35-91; факс: 374-53-30

Исследованы микроструктура и механические свойства образцов сплава MA21, вырезанных из оболочечной конструкции, после 20 -летней эксплуатации в климатических условиях, а также влияние последующих выдержек при температурах 50 и $70{ }^{\circ} \mathrm{C}$ длительностью до 3000 ч на изменение механических свойств и значений удельного электросопротивления. Показано, что сплав МА21 состоит из $\alpha$-твердого раствора легирующих элементов в магнии, $\beta$-твердого раствора легирующих элементов в литии, интерметаллидов алюминия, цинка, магния, марганца и лития MgLiZn и MgLi2Al. При исследованных температурах процессы старения сплава протекают крайне вяло при незначительном снижении значений твердости и сохранении значений удельного электросопротивления. Изменения механических свойств зафиксированы только в первые 1000 часов выдержки при $70{ }^{\circ} \mathrm{C}$.

Ключевые слова: магниевый сплав, микроструктура, интерметаллид, твердость, прочность, старение, удельное электросопротивление

\section{1. Введение}

Сплав МА21 относится к сверхлегким магниево-литиевым деформируемым сплавам значения плотности находятся в интервале $\rho=1300-1600$ кг $/ \mathrm{m}^{3}$, что обеспечивается его легированием литием [1-3]. Сплав используется для средненагруженных деталей, работающих при температурах до $100-125^{\circ} \mathrm{C}$ и криогенных температурах, когда требуется высокая жесткость и повышенная прочность при сжатии. Известно $[1,4,5]$, что литий значительно повышает технологическую пластичность магниевых сплавов. Например, легирование магния 6-14\% Li приводит к значительному (в 2-10 раз) росту пластичности и ударной вязкости при температурах испытания от 196 до $300{ }^{\circ} \mathrm{C}$ и интервале скоростей деформирования 0,005-20 см/мин, прочность при этом уменьшается в 2-3 раза. С увеличением содержания лития в магниевых сплавах снижается их чувствительность к надрезу.

Технологическая пластичность магниево-литиевого сплава MA21, наряду с зависимостью от присутствия в них лития, в значительной мере зависит от содержания основной упрочняющей добавки - алюминия и примесей натрия и калия: увеличение в сплавах содержания натрия и калия более $0,005 \%$ каждого приводит к падению пластичности и технологичности при обработке давлением [6-8]. Добавки алюминия незначительно изменяют растворимость лития в твердом магнии, а прибавление лития к магниево-алюминиевым сплавам приводит к снижению растворимости алюминия в твердом магнии. Область гомогенности 
литиевого твердого раствора значительно сужается с понижением температуры. Кроме лития и алюминия сплав легирован цинком и кадмием, которые способствуют повышению прочностных характеристик $[2,6,9]$.

При эксплуатации листовых или оболочечных крупногабаритных конструкций, предназначенных для хранения веществ большой массы, даже в условиях климатических температур можно ожидать определенных структурных изменений в сплавах этого класса. Оценке свойств подобных конструкций после многолетнего использования посвящены весьма немногочисленные исследования $[10,11]$. Вопрос сохранения стабильности свойств сплавов типа МА21 в течение длительного времени пока остается открытым, поэтому исследования, направленные на определение изменений показателей свойств при температурах, близких климатическим (до $100{ }^{\circ} \mathrm{C}$ ), представляют как научный, так и практический интерес, поскольку они позволяют прогнозировать остаточный ресурс конструкций.

Целью настоящей работы является изучение структуры, механических свойств и изменения значений удельного электросопротивления фрагментов оболочечной конструкции из сплава МА21 после 20 лет эксплуатации в климатических условиях, а также дополнительных термических выдержек при температурах 50 и $70{ }^{\circ} \mathrm{C}$.

\section{2. Материалы и методика эксперимента}

В качестве объектов исследования использованы фрагменты оболочечной конструкции из сплава МА21 после 20 лет эксплуатации в климатических условиях. Металлографические исследования проведены на оптическом микроскопе NEOPHOT-21 при увеличениях 100 и 500 крат. Образцы для исследований готовили на полировальном комплексе LaboPol-2 фирмы Struers. Применение специальных полировальных материалов позволяет исключить внедрение посторонних металлов или неметаллов в поверхность образцов, что очень важно для точного определения химического состава фаз в сплаве.

Твердость материалов по Виккерсу замеряли на твердомере Akashi при нагрузке 5 кг (49 Н). Микротвердость структурных составляющих измеряли на приборе Leica фирмы Leica Microsystems (Germany), оснащенным программным обеспечением «Materials Workstation», позволяющим с доверительной вероятностью 0,95 определять значения микротвердости. Измерения проводили при нагрузке 25 г и скорости нагружения 40 мкм/сек.

Микрорентгеноспектральный анализ выполнен на приборах CAMEBAX и JEOL. Перед проведением точного химического анализа состава фаз приборы позволяют снимать спектр характеристического рентгеновского излучения с данной фазы, формирующийся под воздействием сфокусированного пучка электронов (электронного зонда), определяя тем самым качественный состав материала. Были получены изображения микроструктуры материала в излучении легирующих элементов, распределение элементов по линии сканирования, проходящие через фазы сплава, а также определен точный химический состав в точке поверхности шлифа диаметром 2 мкм с помощью специального программного комплекса программ для автоматического введения поправочных коэффициентов. Локальность метода 2 мкм, погрешность $-5 \%$ от измеряемой концентрации.

Механические испытания проводили на испытательной гидравлической машине INSTRON $8801^{1}$. Особенностью машины является высокая жесткость и точность. Машина оснащена динамически компенсированным датчиком усилия Dynacell, который позволяет производить макимально точные измерения. Датчик снабжен устройством динамической компенсации, которое минимизирует влияние инерции на измерение силы. Размеры и форма образцов для испытаний на статическое растяжение приведены на рис. 1. Испытания на сжатие проводили на цилиндрических образцах диаметром 10 мм и высотой 15 мм.

\footnotetext{
${ }^{1}$ Испытания проведены на оборудовании центра коллективного пользования ИМАШ УрО РАН Pugacheva N.B. et al. / Studying the changes in the structure and properties of a magnesium alloy after operation and long annealing at temperatures of 50 and $70^{\circ} \mathrm{C}$ 

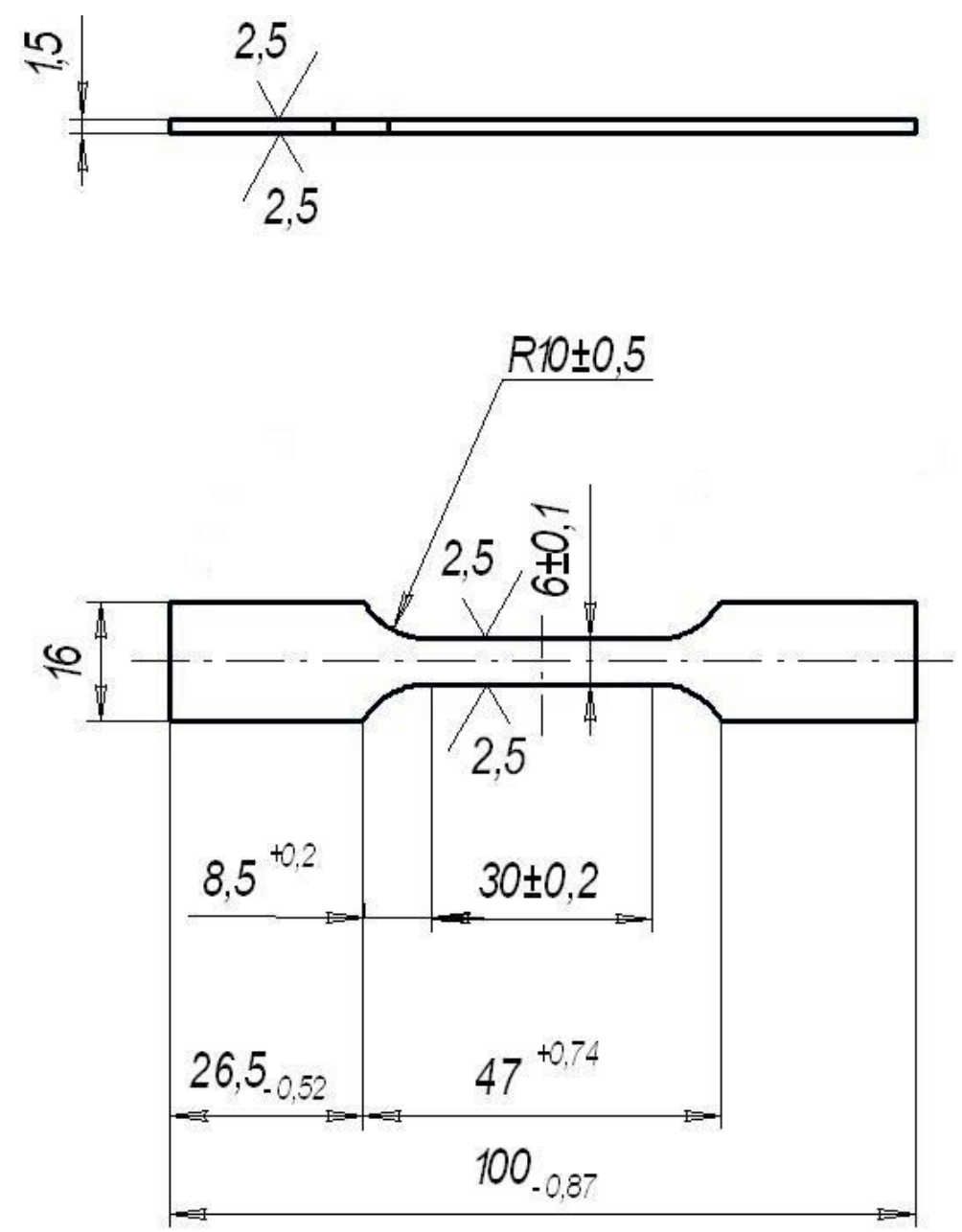

Рис. 1. Форма и размеры образцов для испытаний на растяжение

Измерение удельного электросопротивления образцов проводили с помощью микроомметра БС3-010-2 по четырехпроводной схеме. Прибор имеет на шкале 1000 мОм допускаемую основную приведенную погрешность $\pm(0,1+2$ единицы младшего разряда) при измерительном токе 0,2 А, единица младшего разряда равна 10 мкОм. Измерительная база для потенциальных электродов равна 22 мм. Вычисление величины удельного электросопротивления материала образца проводилось по формуле:

$$
\rho=\frac{R \cdot S}{l}
$$

где $\mathrm{R}$ - электросопротивление материала; $\mathrm{S}$ - площадь поперечного сечения образца; $l$ - измерительная база для потенциальных электродов.

\section{3. Результаты исследований и их обсуждение}

B соответствии с диаграммой состояния $\mathrm{Mg}-\mathrm{Al}-\mathrm{Cd}-\mathrm{Li}$ (рис. 2) основой сплава MA21 является двухфазная $(\alpha+\beta)$ структура, где $\alpha$ - твердый раствор на основе магния с ГПУ решеткой и $\beta$ - твердый раствор на основе лития с ОЦК решеткой. Растворимость лития в твердом магнии при эвтектической температуре составляет 5,5 \% и практически не изменяется при понижении температуры (при $300{ }^{\circ} \mathrm{C}-5,7 \%$ ) [1-3]. Растворимость магния в литии при эвтектической температуре - 91,5 масс. \% (75,5 ат. \%), она заметно изменяется при понижении температуры и при $100{ }^{\circ} \mathrm{C}$ составляет 89 масс. \% [4]. 
open-access journal

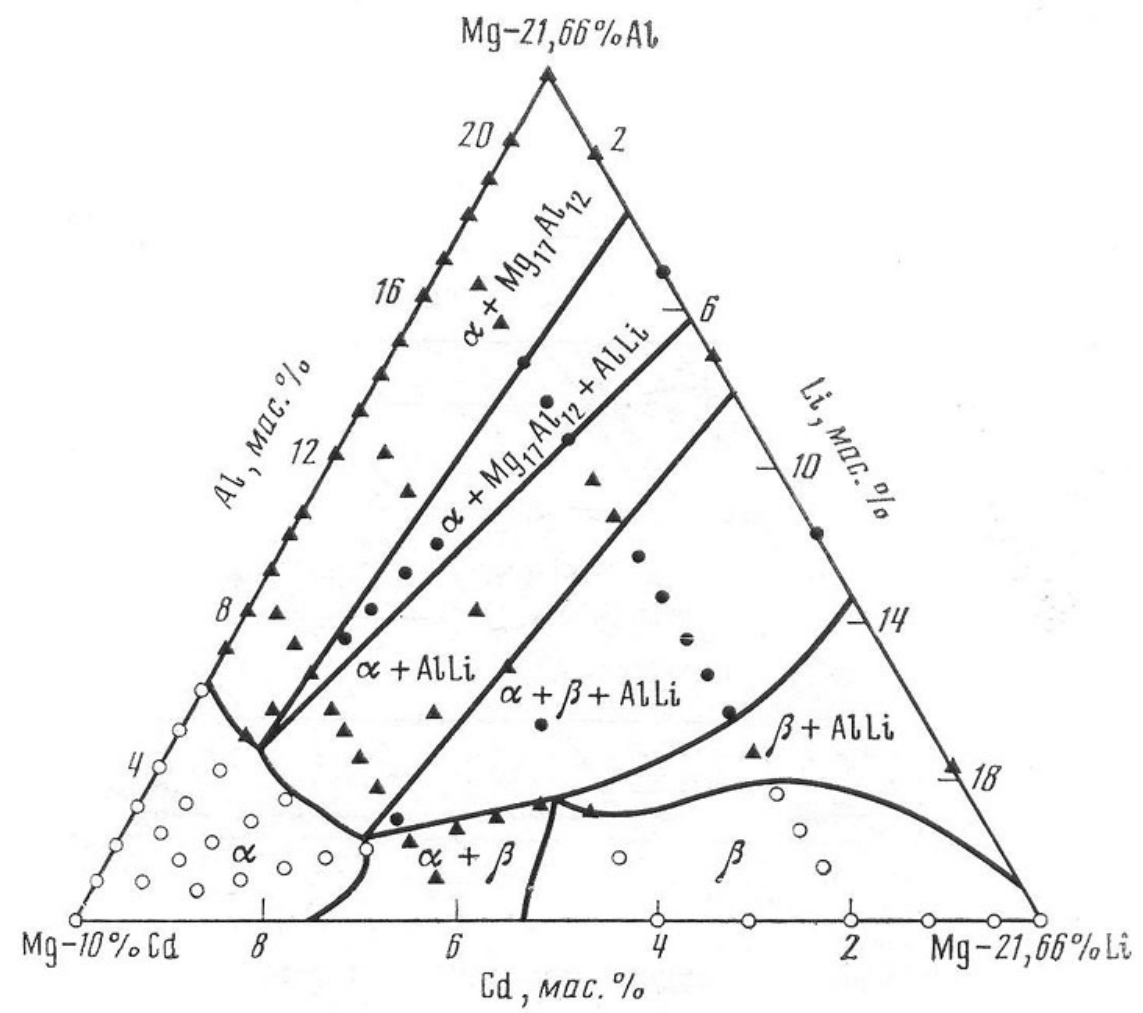

Рис. 2. Разрез диаграммы состояния системы $\mathrm{Mg}-\mathrm{Al}-\mathrm{Li}-\mathrm{Cd}$ [3]

Исследованный сплав МА21 имеет гетерофазную структуру: светлые зерна $\alpha$ - твердого раствора на основе магния с ГПУ решеткой и более темные $\beta$ - твердого раствора на основе лития с ОЦК решеткой (рис. 3). Алюминий в большей степени растворяется в $\alpha$ - твердом растворе по сравнению с $\beta$ - фазой, а цинк и кальций образуют самостоятельные фазы (рис. 4). Следует отметить, что определение содержания лития в структурных составляющих микрорентгеноспектральным методом крайне затруднено, так как определяется по разности от $100 \%$ и суммы всех остальных элементов. Аналогично проводится и определение содержания кислорода, который всегда в некотором количестве присутствует на поверхности шлифов магниевых сплавов, так как они быстро окисляются. Поэтому в табл. 1 указано суммарное содержание этих двух элементов в колонке Li.

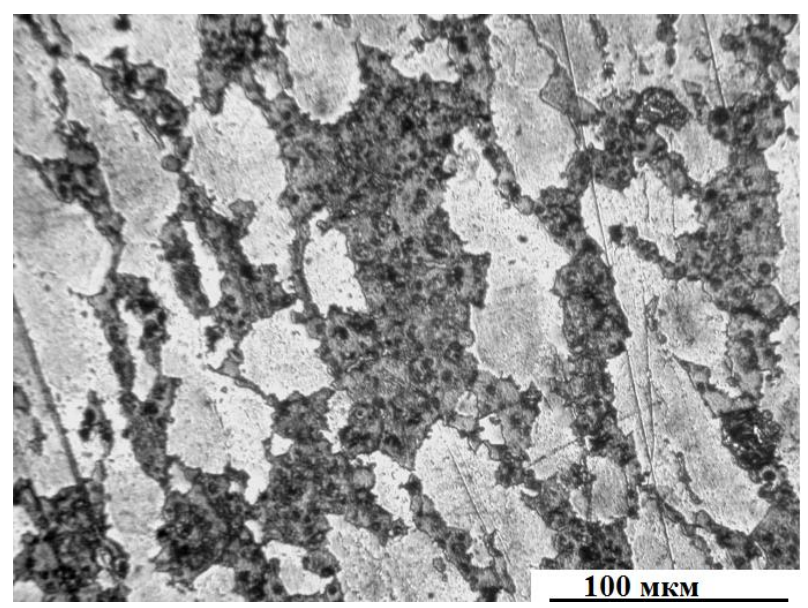

Рис. 3. Микроструктура сплава МА21

Pugacheva N.B. et al. / Studying the changes in the structure and properties of a magnesium alloy after operation and long annealing at temperatures of 50 and $70{ }^{\circ} \mathrm{C}$ 
По результатам определения локального химического состава исследованного сплава различимы 4 разные фазы (см. табл. 1). Светлые зерна (см. рис. 3; область 1 на рис. 5) представляют собой $\alpha$-твердый раствор легирующих элементов в магнии, содержащий 6 масс. \% $\mathrm{Al}, 4$ масс. \% $\mathrm{Cd}, 1$ масс. \% Zn, и порядка 2,5 масс. \% Li. Твердость этих участков составляет $76,4 \mathrm{HV}$ 0,025. Более темные участки обогащены литием (15 масс. \%) и кадмием (6 масс. \%) и практически не содержат алюминия - область 2 на рис.5 и в табл.1. Твердость этих участков немного ниже по сравнению с $\alpha$-фазой и составляет 66,2 HV 0,025.

Таблица 1 - Химический состав структурных составляющих сплава МА21, масс. \%

\begin{tabular}{|c|c|c|c|c|c|c|c|c|c|c|c|c|c|}
\hline \multirow{2}{*}{ № } & \multirow{2}{*}{$\begin{array}{c}\text { № } \\
\text { структурной } \\
\text { составляющей }\end{array}$} & \multicolumn{12}{|c|}{ Химический состав. масс. \% } \\
\hline & & $\mathrm{Mg}$ & $\mathrm{Al}$ & $\mathrm{Zn}$ & $\mathrm{Cd}$ & $\mathrm{Li}+\mathrm{O}_{2}$ & $\mathrm{Mn}$ & P3M & $\mathrm{Ni}$ & $\mathrm{Cu}$ & $\mathrm{Si}$ & $\mathrm{Na}$ & $\mathrm{Ca}$ \\
\hline 1 & $\begin{array}{c}\text { Справочные } \\
\text { данные для } \\
\text { сплава } \\
\end{array}$ & $\begin{array}{l}\text { остал } \\
\text { ьное }\end{array}$ & $4-6$ & $8-2$ & $3-5$ & $7-10$ & $\begin{array}{l}0,15 \\
-0,5\end{array}$ & $\begin{array}{c}0,05 \\
- \\
0,15 \\
\end{array}$ & 0 & 0 & 0 & 0 & 0 \\
\hline 2 & $1(\alpha)$ & 86,5 & 6 & 1 & 4 & 2,5 & 0,08 & 0,01 & 0,01 & 0,01 & 0,02 & 0,01 & 0,01 \\
\hline 3 & $2(\mathrm{Mg}-\mathrm{Li}-\mathrm{Cd})$ & 78 & 0,6 & 0,5 & 6 & 15 & 0,06 & 0,01 & 0,01 & 0,01 & 0,07 & 0,01 & 0,01 \\
\hline 4 & $\begin{array}{c}3(\mathrm{Mg}-\mathrm{Al}-\mathrm{Li}- \\
\mathrm{Zn}-\mathrm{Cd})\end{array}$ & 37,5 & 22,3 & 9,6 & 5,3 & 22,7 & 0,06 & 0,01 & 0,01 & 0,01 & 0,32 & 0,02 & 2,3 \\
\hline 5 & $\begin{array}{c}4(\mathrm{Mg}-\mathrm{Al}-\mathrm{Li}- \\
\mathrm{Zn}-\mathrm{Cd})\end{array}$ & 39,5 & 16,6 & 7,3 & 5,3 & 31,8 & 0,06 & 0,01 & 0,01 & 0,01 & 0,3 & 0,02 & 0,01 \\
\hline
\end{tabular}

Фаза 3 на рис. 5 и в табл. 1 соответствует интерметаллиду MgAlLiZnCd, частицы которого образуют строчечные скопления, внутри которых присутствуют единичные частицы кальция (см. рис. 4 в). Фаза 4 на рис. 5 и в табл. 1 представляет собой также интерметаллид $\mathrm{MgAlLiZnCd,} \mathrm{но} \mathrm{с} \mathrm{большим} \mathrm{содержанием} \mathrm{лития.} \mathrm{Фаза} 3$ отличается от фазы 4 более высоким содержанием алюминия и цинка. Следует отметить, что при определении химического состава частиц, размер которых составляет 2-5 мкм, возникает ошибка, связанная с тем, что зонд захватывает окружающий эти частицы материал сплава. При этом фиксируемая концентрация магния в анализируемых частицах завышена (реально его может вообще не быть в частице), а концентрации алюминия и цинка - занижены.

По величине предела прочности экспериментальные данные, полученные на образцах, вырезанных из оболочечной конструкции после 20 лет эксплуатации, удовлетворяют требованиям конструкторской документации для сплава МА21 (табл. 2). Два из четырех испытанных на сжатие образцов имели значение предела текучести 156 МПа при требуемом минимуме 157 МПа. Следует отметить общее снижение и прочностных характеристик и пластичности сплава после эксплуатации. Величина разброса экспериментальных данных по пределу прочности составляет 0,9 \%. По величине условного предела текучести экспериментальные данные испытаний на растяжение удовлетворяют, а испытаний на сжатие удовлетворяют частично (2 из 4 испытанных образцов). Величина разброса экспериментальных данных по условному пределу текучести для испытаний на растяжение составляет 4 \%, для испытаний на сжатие - $1,9 \%$. По величине относительного удлинения экспериментальные данные удовлетворяют нормируемым требованиям, величина разброса экспериментальных данных составляет $37,8 \%$. 
open-aCCess journal

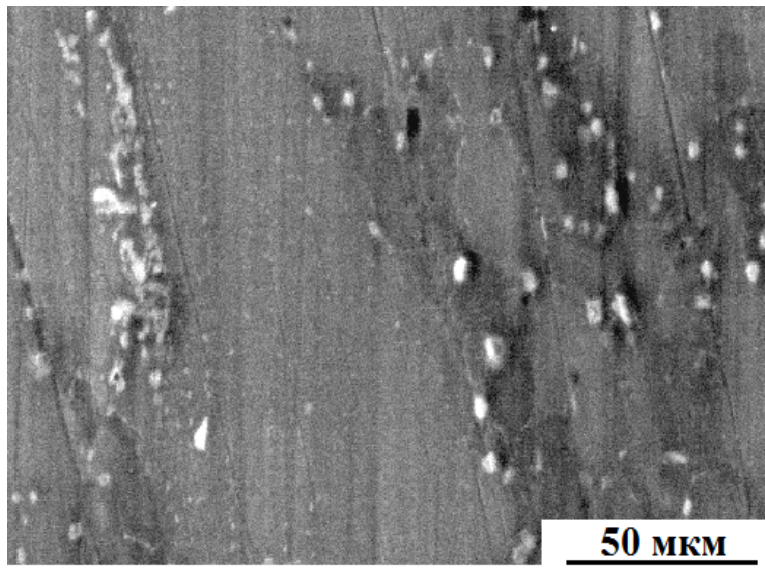

$a$

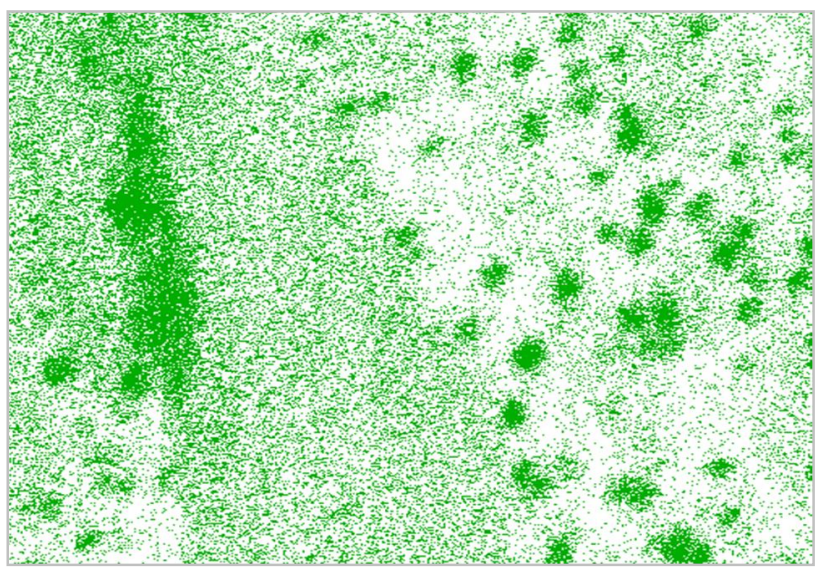

B

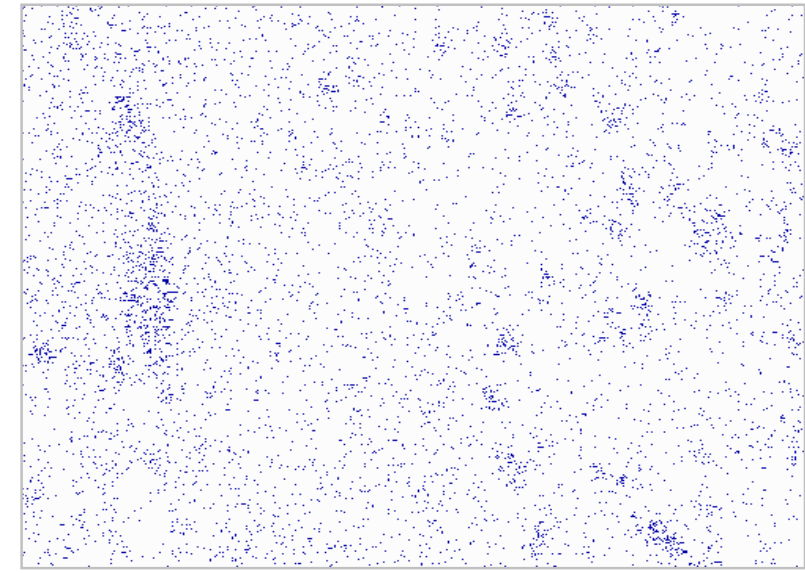

$\sigma$

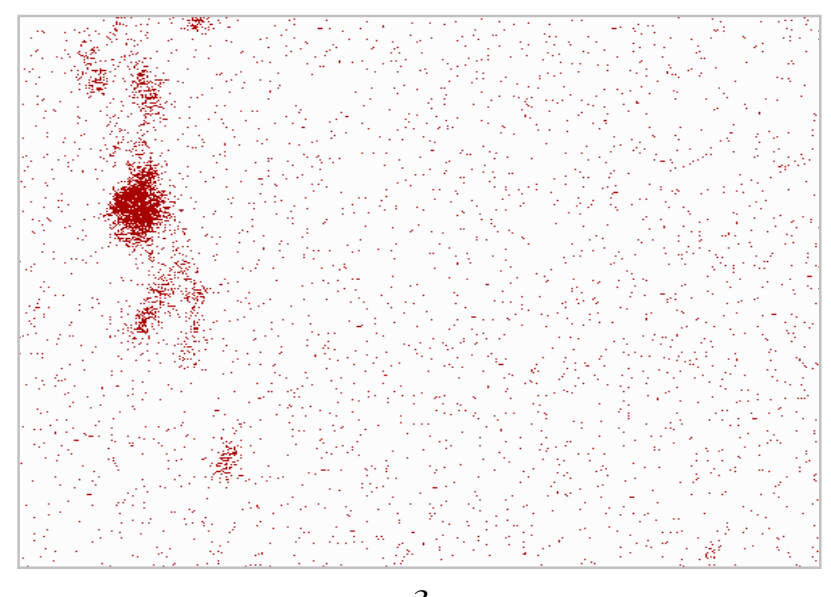

2

Рис. 4. Характер распределения элементов между структурными составляющими сплава MA21: $a$ - изображение во вторичных электронах; $\sigma$ - изображение в характеристическом рентгеновском излучении $\mathrm{Zn} ;$ в - $\mathrm{Al} ; 2-\mathrm{Ca}$

Выдержки при температуре $70{ }^{\circ} \mathrm{C}$ привели к разупрочнению сплава, тогда как при температуре $50{ }^{\circ} \mathrm{C}$ изменений твердости практически не зафиксировано (рис. 6). Значения прочности для сплава МА21 после выдержек при температуре $70{ }^{\circ} \mathrm{C}$ в первые часы немного снижаются при повышении пластичности, а затем стабилизируются на уровне исходных значений (рис. 7). Авторы [2, 3] отмечают, что особенностью магниевых сплавов, содержащих $\mathrm{Li}$, является возможность естественного старения. Известно [2 - 4, 12], что упрочнение в сплаве МА21 обусловлено распадом пересыщенного легирующими элементами $\beta$-твердого раствора на основе лития с ОЦК решеткой: $\beta \rightarrow \mathrm{MgLi}_{2} \mathrm{Al} \rightarrow \mathrm{AlLi} ; \beta \rightarrow \mathrm{MgLi}_{2} \mathrm{Zn} \rightarrow \mathrm{ZnLi}$ (или MgLiZn). 


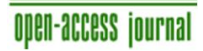
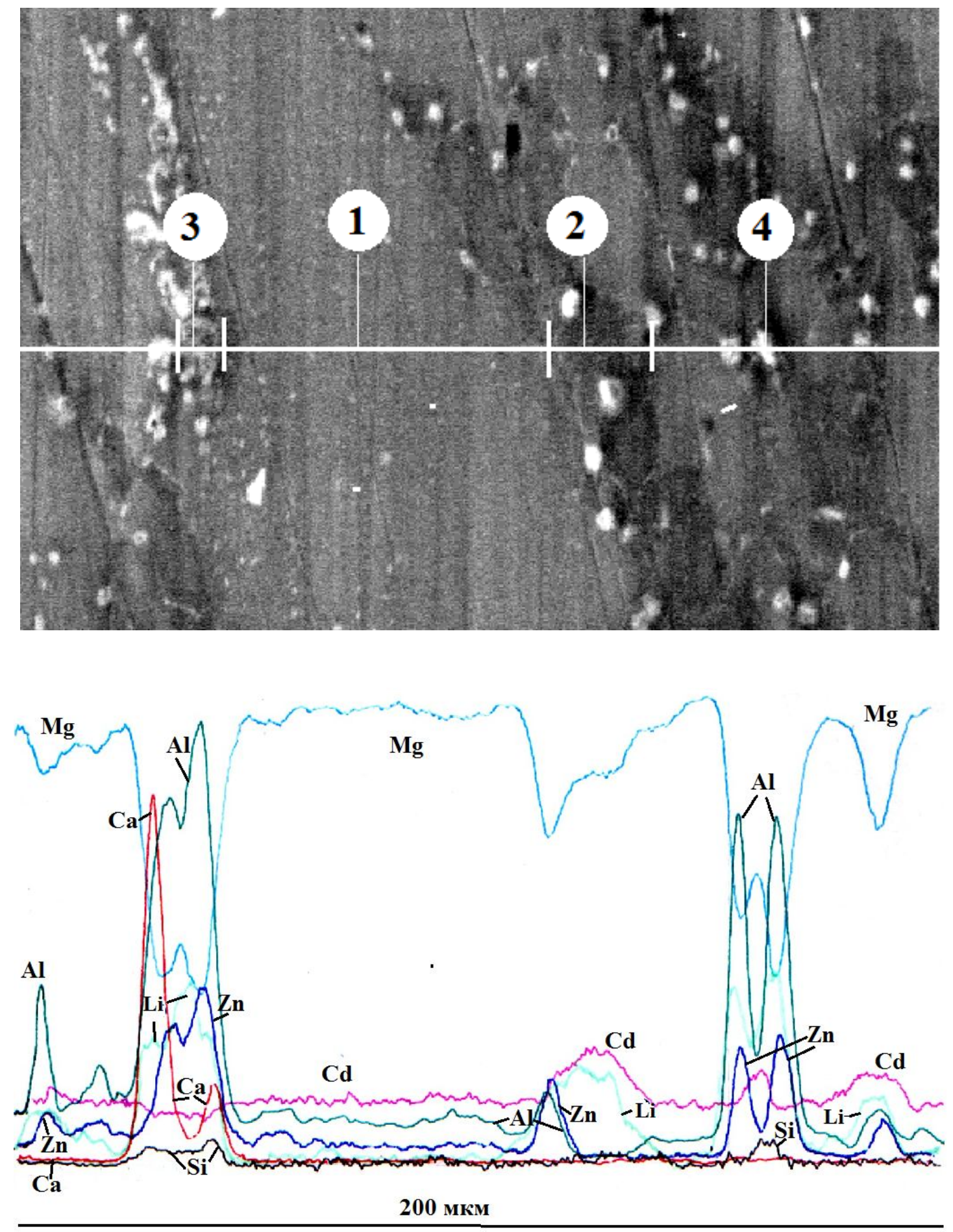

Рис. 5. Характер распределения элементов меду структурными составляющими сплава МА21

Pugacheva N.B. et al. / Studying the changes in the structure and properties of a magnesium alloy after operation and long annealing at temperatures of 50 and $70{ }^{\circ} \mathrm{C}$ 
Таблица 2 - Механические свойства сплава МА21 в исходном состоянии и после эксплуатации

\begin{tabular}{|c|c|c|c|c|c|}
\hline \multirow{2}{*}{$\begin{array}{c}\text { Вид } \\
\text { испытаний }\end{array}$} & \multirow{2}{*}{$\begin{array}{c}\text { Время определения } \\
\text { свойств }\end{array}$} & \multicolumn{4}{|c|}{ Механические свойства мин-макс/среднее } \\
\hline & & $\sigma_{\mathrm{B}}, \mathrm{M \Pi а}$ & $\sigma_{0,2}, \mathrm{M \Pi а}$ & $\delta, \%$ & $\varphi, \%$ \\
\hline \multirow[t]{3}{*}{ Растяжение } & $\begin{array}{c}\text { исходное состояние } \\
\text { сплава }\end{array}$ & $216-224$ & $153-164$ & $17,6-20,8$ & - \\
\hline & $\begin{array}{c}\text { после } 20 \text { лет экс- } \\
\text { плуатации }\end{array}$ & $\frac{217-219}{217,7}$ & $\frac{144-150}{148}$ & $\frac{9,2-14,8}{11,4}$ & $\frac{13,3-18,4}{15,6}$ \\
\hline & $\begin{array}{c}\text { требования кон- } \\
\text { структорской доку- } \\
\text { ментации, не менее }\end{array}$ & 196 & 127 & 8 & - \\
\hline \multirow[t]{3}{*}{ Сжатие } & $\begin{array}{c}\text { исходное состояние } \\
\text { сплава } \\
\end{array}$ & - & $192-206$ & - & - \\
\hline & $\begin{array}{c}\text { после } 20 \text { лет экс- } \\
\text { плуатации }\end{array}$ & $\frac{454-463}{458}$ & $\frac{156-159}{157}$ & - & - \\
\hline & $\begin{array}{c}\text { требования кон- } \\
\text { структорской доку- } \\
\text { ментации, не менее }\end{array}$ & - & 157 & - & - \\
\hline
\end{tabular}

Метастабильные фазы $\mathrm{MgLi}_{2} \mathrm{Al}$ и $\mathrm{MgLi}_{2} \mathrm{Zn}$ когерентны по отношению к матрице, несоответствие параметров кристаллических решеток составляет примерно $5 \%$. Старение в сплавах типа МА21 зафиксировано при довольно низких температурах, поскольку диффузионная подвижность атомов в ОЦК решетке значительно больше, чем в плотноупакованных структурах (ГЦК или ГП). Возможно, некоторое колебание значений механических свойств в первые 1000 часов выдержки при температуре $70{ }^{\circ} \mathrm{C}$ вызвано изменением состояния метастабильных фаз $\mathrm{MgLi}_{2} \mathrm{Al}$ и $\mathrm{MgLi}_{2} \mathrm{Zn}$ и переходом их в стабильные фазы MgAlLi и MgLiZn.

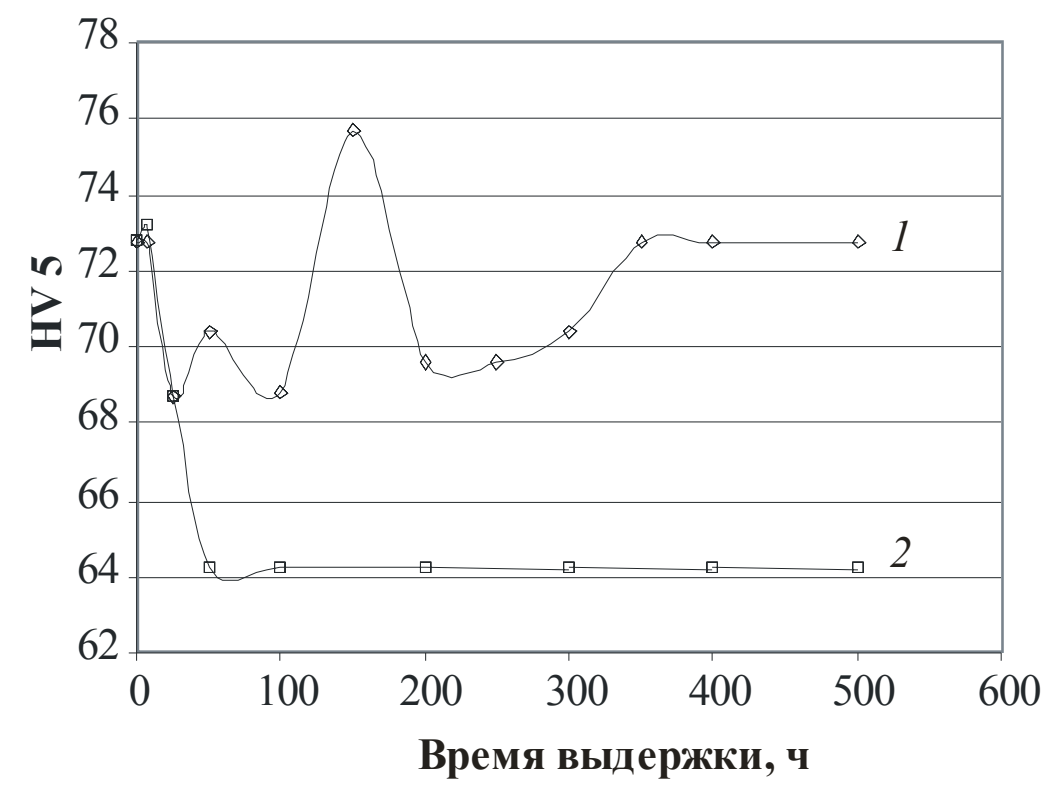

Рис. 6. Изменение значений твердости сплава MА21 после выдержек при температурах $50(1)$ и $70{ }^{\circ} \mathrm{C}(2)$

Значения удельного электросопротивления исследованных образцов практически одинаковы, разброс значений не превышает 0,8 \% (рис. 8), что говорит о сохранении неизменным количества точечных дефектов в сплаве и отсутствии какого-либо заметного их вза- 
open-aceess journal

имодействия с дислокациями при температуре выдержки $70{ }^{\circ} \mathrm{C}$. Как отмечалось ранее в работе [11], изменения прочностных свойств сплава МА21 могут быть связаны только с диффузионными превращениями, а именно - с выделением частиц интерметаллидов из пересыщенного твердого раствора. Следует отметить, что процесс старения при температуре $70{ }^{\circ} \mathrm{C}$ происходит крайне вяло, после выдержки более 1000 часов происходит стабилизация свойств на исходном уровне, что позволяет предполагать стабильность прочностных свойств оболочечной конструкции из сплава МА21 в течение весьма продолжительного периода эксплуатации в климатических условиях.
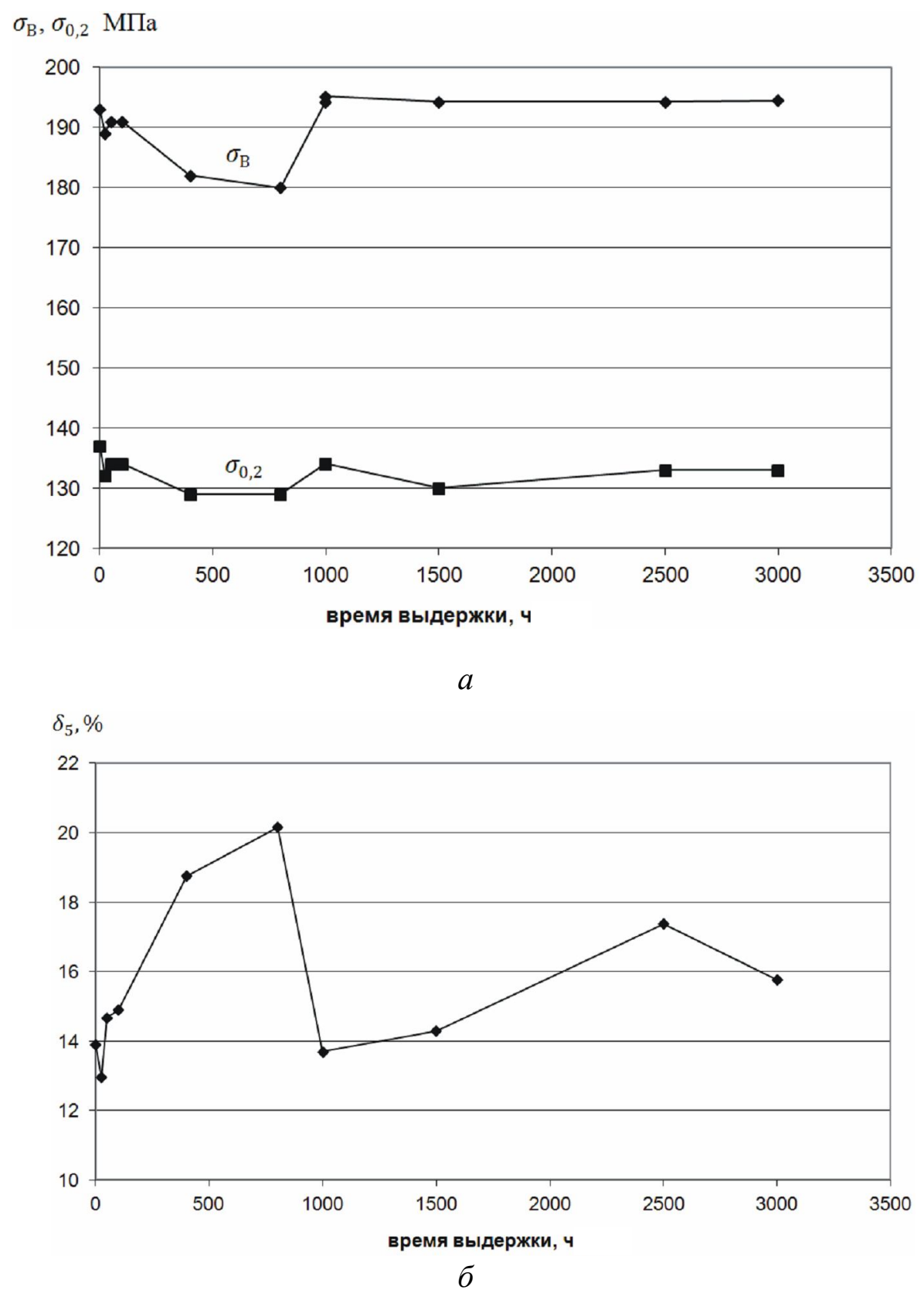

Рис. 7. Изменение прочностных характеристик сплава МА21 после выдержек при температуре $70{ }^{\circ} \mathrm{C}$ 


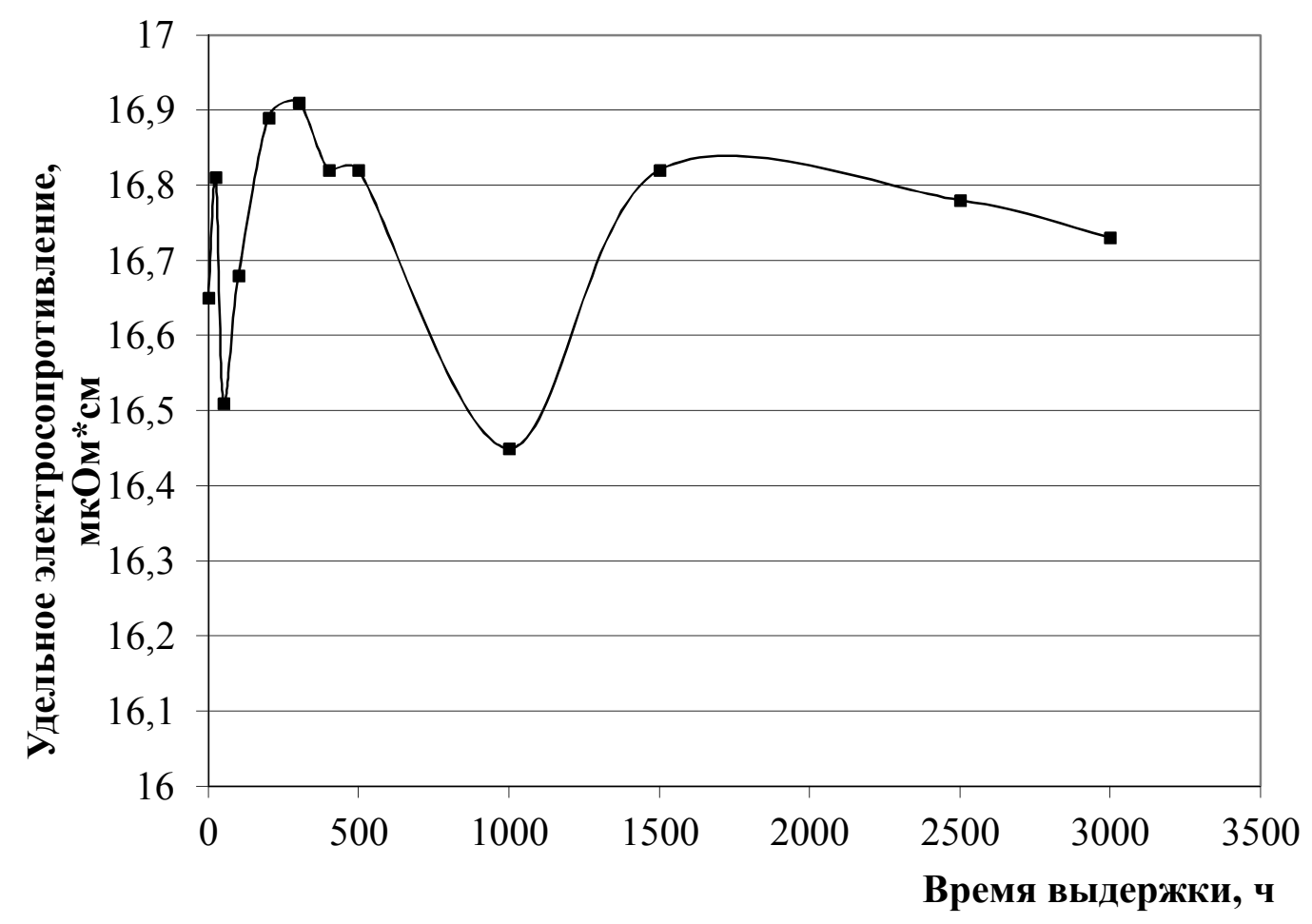

Рис. 8 Изменение значений удельного электросопротивления образцов сплава МА21 после выдержек при температуре $70^{\circ} \mathrm{C}$

\section{4. Заключение}

Исследованный сплав МА21 имеет следующий фазовый состав: $\alpha$-твердый раствор легирующих элементов в магнии, $\beta$-твердый раствор легирующих элементов в литии, интерметаллиды, содержащие алюминий, цинк, литий, магний и кадмий.

Анализ прочностного состояния сплава MA21 в оболочечной конструкции после 20 лет эксплуатации в климатических условиях показал соответствие минимальным значениям нормативных требований конструкторской документации. Весьма незначительное отклонение от нормы наблюдали только при испытаниях на сжатие, но его можно отнести к колебаниям значений в пределах ошибки изменения этой величины.

Исследования прочностных свойств образцов из сплава МА21, вырезанных из элементов конструкции после 20 лет эксплуатации, в течение длительных выдержек при 50 и 70 ${ }^{\circ} \mathrm{C}$ показали, что при $50{ }^{\circ} \mathrm{C}$ никаких изменений состояния сплава не происходит, при $70{ }^{\circ} \mathrm{C}$ процессы старения развиваются крайне слабо и стабилизируются во времени, не изменяя механических свойств сплава.

Твердость является более чувствительной характеристикой разупрочнения сплава MA21 по сравнению с механическими свойствами: изменения её значений были зафиксированы в первые часы выдержки при температуре $70{ }^{\circ} \mathrm{C}$, тогда как при температуре $50{ }^{\circ} \mathrm{C}$ разупрочнения сплава не произошло.

При температурах выдержек 50 и $70{ }^{\circ} \mathrm{C}$ не зафиксировано каких-либо заметных изменений значений удельного электросопротивления, что свидетельствует о сохранении плотности точечных дефектов в сплаве.

Проведенные исследования показали устойчивость механических свойств сплава MA21 при температурах 50 и $70{ }^{\circ} \mathrm{C}$, что дает гарантии сохранения его основных характеристик в течение длительного времени эксплуатации при климатических температурах. 
open-aCCESS journal

\section{Благодарность}

Работа выполнена в соответствии с планом Фундаментальных научных исследований государственных академий наук на 2013-2020 г. по теме № 01201375904.

\section{Литература}

1. Колачев Б. А., Елагин В. И., Ливанов В. А. Металловедение и термическая обработка цветных металлов и сплавов. - М. : Изд-во МИСИС, 2001. - 416 с.

2. Машиностроение. Энциклопедия. Том II-3. Цветные металлы и сплавы. Композиционные металлические материалы / под ред. И. Н. Фридляндера. - М. : Машиностроение, 2001. $-880 \mathrm{c}$.

3. Фридляндер И. Н. Современные алюминиевые, магниевые сплавы и композиционные материалы на их основе // Металловедение и термическая обработка металлов. - 2002. - № 7. - C. $24-29$.

4. Дриц М. Е., Падежнова Е. М., Рохлин А. И. Легкие сплавы, содержащие литий : монография / под ред. Н. Х. Абрикосова. - М. : Наука, 1982. - 143 с.

5. Свойства элементов. : в 2 т. / под ред. Г. В. Самсонова. - М. : Металлургия, 1976. T. $1 .-600$ c. - T. $2 .-383$ c.

6. Магниевые сплавы. Справочник. Ч. 1. Металловедение магния и его сплавов. Области применения. - М. : Металлургия, 1978. - 232 с.

7. Туркин В. Д, Румянцев М. В. Структура и свойства цветных металлов. - М.: Гос. науч.-техн. изд-во лит. по чер. и цв. металлургии, 1947. -440 с

8. Легкие цветные металлы и сплавы : справочник / Л. Н. Дорохина, 3. А. Таужнянская, Л. Ф. Никерова, Г. Н. Кручер / под общ. ред. С. Н. Подвишенского, М. В. Теслицкой. - М. : ФГУП “ЦНИИЭцветмет”, 2001. - Т. 2. - 416 с.

9. Техническая энциклопедия / под ред. Л. К. Мартенса. - М. : Гостехиздат ОГИЗ, 1941. - T. $12 .-855$ c.

10. Изучение и моделирование возврата в сплаве АМг6 с целью прогнозирования ресурса эксплуатации деталей авиакосмической техники / Д. А. Мирзаев, Ю. Д. Карягин, Я. С. Добрынина, А. А. Звонков // Физика металлов и металловедение. - 2004. - Т. 98, № 8. C. $11-18$.

11. Прогнозирование изменения предела текучести, обусловленного диффузионными превращениями, в сплаве МА21 в ходе многолетней выдержки // Д. А. Мирзаев, Ю. Д. Карягин, К. Ю. Окишев, В. М. Елгин, А. А. Звонков // Вестник Южно-уральского государственного университета. Серия: Математика. Механика. Физика. - 2006. - № 7. - С. 199 - 202.

12. Рохлин Л. Л. Исследование кинетики распада пересыщенного твердого раствора в сплавах магния с иттрием // Металловедение и термическая обработка металлов. - 1987. № 3. С. $50-52$. 